\title{
Limited Proliferative Potential of Primitive Hematopoietic Stem Cells: Hematopoiesis by Clonal Succession
}

\author{
J.L. Chertkov, E.I. Deryugina, N.J. Drize, and E.Yu. Sadovnikova
}

\section{A. Introduction}

The hierarchy of hematopoietic stem cells (HSC) is represented by several categories of maturating pluripotent progenitors. Most of them are the members of transitional cell populations and, obviously, have no capacity for self-maintenance, i.e., are not capable of giving rise to self-replicating offspring with the same proliferative potential as the parent had [1]. The foundator of this hierarchy has not yet been identified. The most probable candidate at present is the cells supporting long-term hematopoiesis in vivo after repopulation of lethally irradiated or genetically defective W-mutant mice or in vitro in long-term culture. However, the self-renewal is also not proven for these cells, and hematopoiesis, at least in culture, occurs by clonal succession [2]. The experimental data support the hypothesis that even primitive HSC (PHSC) exhibit high, though limited, proliferative potential. This cell category is usually identified by competitive repopulation assay using a mixture of tested and standard cells identifiable by biochemical, immunological, karyological, or other markers [3]. Limiting dilution analysis based on the ability of small numbers of $+/+$ hematopoietic cells to cure anemia of W-mutant mice has been also used for the determination of PHSC [4-6].

In the present study, the characteristics of PHSC were investigated in long-term bone marrow culture by both competi-

Hematological Scientific Center, Moscow, U.S.S.R., 125167 tive repopulation and limiting dilution methods. Primitive HSC were defined as precursors responsible for the long-term maintenance of hematopoiesis, i.e., for the generation of mature as well as progenitor hematopoietic cells, particularly CFUs.

\section{B. Materials and Methods \\ I. Mice}

Eight- to 12-week-old male and female $(\mathrm{CBA} \times \mathrm{C} 57 \mathrm{BL} / 6) \mathrm{F}_{1}(\mathrm{CBF})$ and $(\mathrm{C} 57 \mathrm{BL} / 6$ $\times \mathrm{DBA} / 2) \mathrm{F}_{1}(\mathrm{BDF})$ mice were used.

\section{Irradiation}

A ${ }^{137} \mathrm{Cs}$-IPK irradiator was used. The recipient mice were irradiated with $13 \mathrm{~Gy}$, the donor mice were sublethally irradiated with 2 or $4 \mathrm{~Gy}$, at a dose rate of $20 \mathrm{cGy} / \mathrm{min}$. The cultures were irradiated with $12 \mathrm{~Gy}$ at a dose rate of $4.5 \mathrm{~Gy} /$ $\min$.

\section{CFUs Determination}

The spleen colony assay was used [7]. The recipient mice (8-10 per group) were injected with hematopoietic cells, and spleen colonies were counted 8 days later.

\section{Long-Term Bone Marrow Culture}

The Dexter method of culture [8] was used as described elsewhere [9]. Briefly, the contents of a femur were flushed into a $25-\mathrm{cm}^{2}$ tissue culture flask (Lux) containing $10 \mathrm{ml}$ of Fisher medium supplemented with $14 \%$ horse serum, $7 \%$ fetal calf serum (all Flow), and $10^{-6} M$ hydro- 
cortisone sodium succinate (Sigma). The cultures were tightly sealed and placed in a dry $33^{\circ} \mathrm{C}$ incubator. One half of the medium with nonadherent cells was replaced weekly. In 3 weeks, after adherent cell layer formation, the cultures were irradiated and, after decanting of all medium with nonadherent cells, recharged with hematopoietic cells for competitive repopulation or for limiting dilution analysis.

\section{Limiting Dilution Analysis}

Irradiated 3-week cultures (at least 20 per point) were seeded with two doses of bone marrow cells: 0.01 or 0.0033 femur equivalent (f.e) per flask. At 5 (CBF mice) or 7 (BDF mice) weeks the individual cultures were scraped off with a rubber policeman and after repeated pipetting, both adherent and nonadherent cells from each culture were injected i.v. into two lethally irradiated mice for the verification of the presence of CFUs. The PHSC number $(\mathrm{N})$, according to the equation $\mathrm{N}=-\ln \mathrm{P}_{0}$, was determined by evaluation of the fraction of cultures in which CFUs were not revealed $\left(\mathrm{P}_{0}\right)$.

\section{Competitive Repopulation}

The repopulating abilities of sublethally irradiated hematopoietic cells immediately after irradiation and those after regeneration were compared. The cultures were seeded with an equal mixture of bone marrow cells from mice irradiated just prior to the explantation and from mice of another genotype irradiated 10 or 19 weeks before explantation. Cell suspension was obtained by pooling equal amounts of bone marrow cells from CBF and BDF mice, and was used for the recharging of cultures (1-2 f.e./flask). The proportion of CFUs of each genotype was determined after 2-6 weeks in the nonadherent cell fraction. To discriminate the origin of the CFUs the mice of both genotypes were injected with the same mixture of pooled nonadherent cells. Previously, the recipients had been immunized i.p. more than twice, and not later than 2 months prior to the experiment with $2-3 \times 10^{7}$ spleen cells (CBF mice with $\mathrm{DBA} / 2$ spleen cells and $\mathrm{BDF}$ mice with $\mathrm{CBA}$ spleen cells). The syngeneic CFUs gave rise to the same spleen colony number in both immunized and nonimmunized recipients, whereas semiallogeneic CFUs did not generate spleen colonies in immunized mice (data not shown).

\section{Chimeras}

Irradiated recipients were injected with $0.35 \times 10^{6}$ or $35 \times 10^{6}$ syngeneic bone marrow cells. PHSC determination was performed by limiting dilution analysis 6 or 7.5 months after reconstitution.

\section{Cytostatics}

Hydroxyurea $(900 \mathrm{mg} / \mathrm{kg})$ was injected i. p. six times at 6-h intervals, and donor mice were killed $2 \mathrm{~h}$ after the last injection. 5-Fluorouracil $(150 \mathrm{mg} / \mathrm{kg})$ was injected i.v., and donor mice were killed 2 or 4 days later.

\section{Results}

A significant correlation between the number of explanted bone marrow cells and the estimated amount of PHSC was observed, the linear regression line going through the origin (Fig. 1). Thus, the data suggest that the number of PHSC may be determined by the limiting dilution method. The content of PHSC in murine bone marrow as estimated by this method was $90 \pm 20$ per femur.

The treatment of donor mice with cytostatics revealed that PHSC are insensitive to the drugs used. Neither intensive treatment with hydroxyurea nor the injection of 5-fluorouracil essentially reduced the number of PHSC in bone marrow in spite of the fact that both drugs killed more than $99 \%$ of CFUs (Table 1 ).

Six or 7.5 months after the reconstitution, the number of PHSC in mice injected with a "small" dose $\left(0.35 \times 10^{6}\right)$ of bone marrow cells was lower than in 
Table 1. The effect of phase-specific cytostatics on CFUs and PHSC content in murine bone marrow as measured by limiting dilution method

\begin{tabular}{llcc}
\hline Drug & $\begin{array}{l}\text { Time after } \\
\text { treatment }\end{array}$ & CFUs/femur & PHSC/femur \\
\hline- & - & 7680 & 79 \\
Hydroxyurea & 2 hours & 79 & 65 \\
5-Fluorouracil & 2 days & 28 & 53 \\
& 4 days & 191 & 45 \\
\hline
\end{tabular}
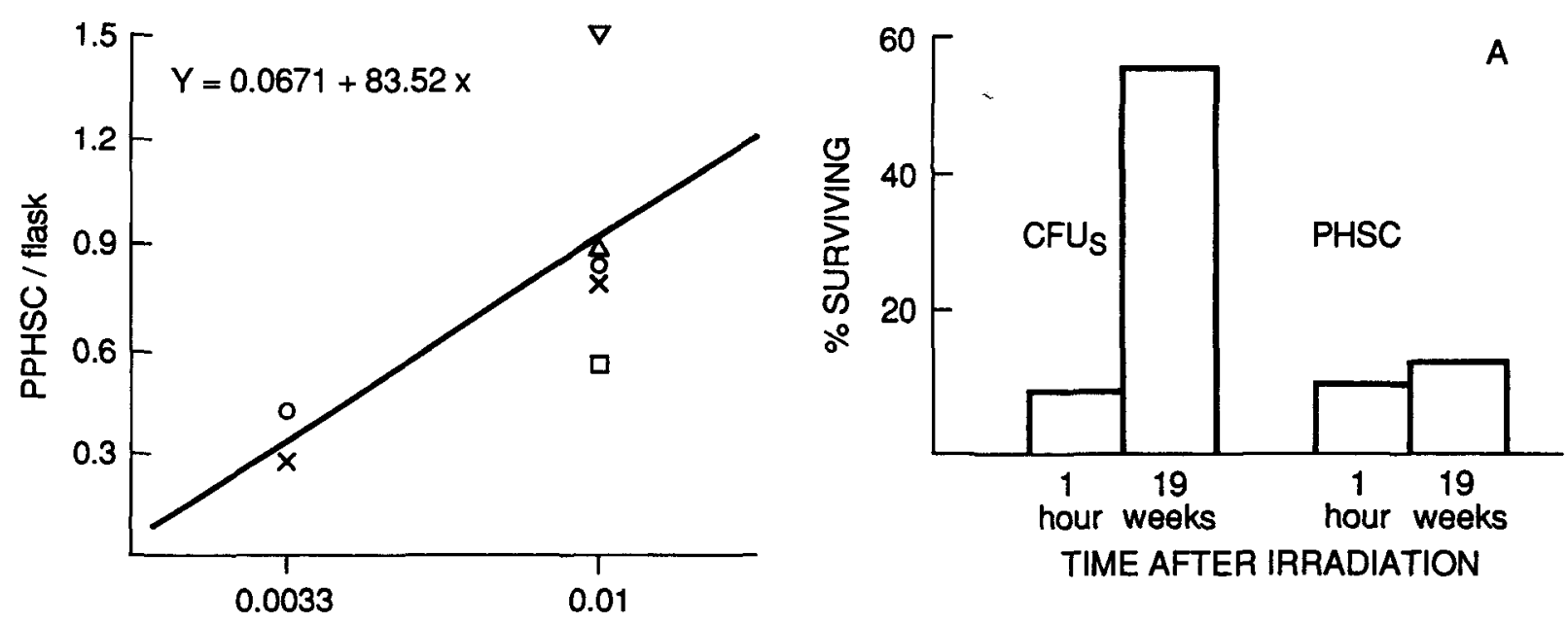

\section{BONE MARROW CELLS SEEDED \\ (femur equivalent / flask)}

Fig. 1. Primitive hematopoietic stem cell content in normal mice as measured by limiting dilution analysis

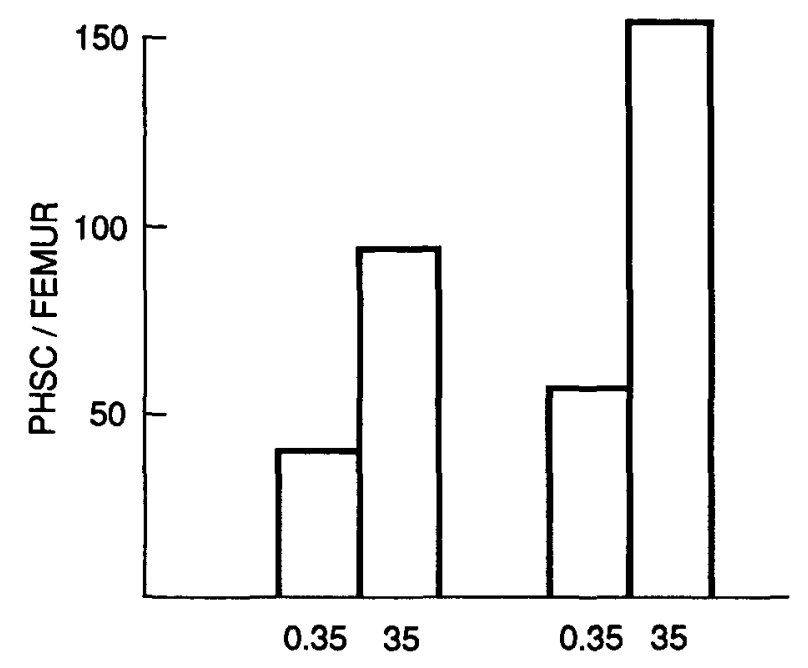

dose of injected bone marrow cells, $\times 10^{-6}$

6

7.5

TIME AFTER RECONSTITUTION (MONTHS)

Fig. 2. Primitive hematopoietic stem cell content in mice reconstituted with different doses of bone marrow cells

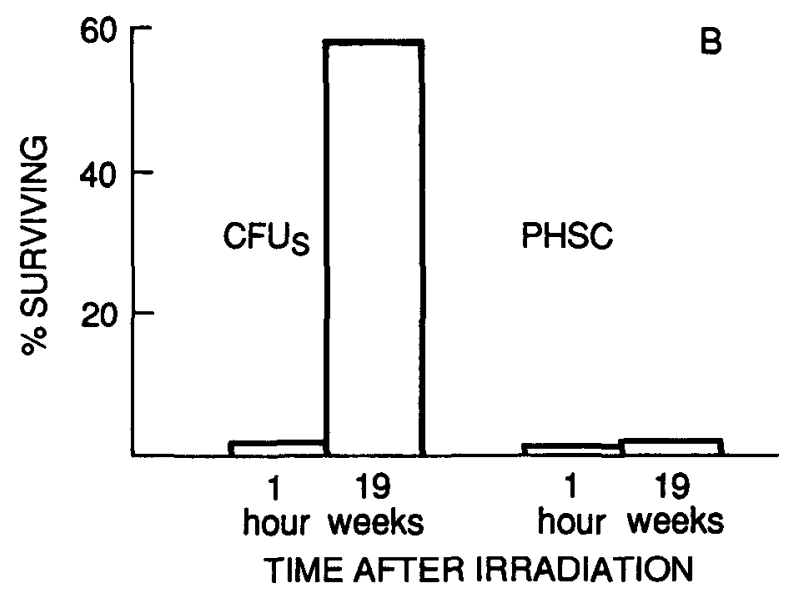

Fig. 3. Primitive hematopoietic stem cell content in bone marrow from mice immediately and 19 weeks after irradiation with a dose of $2 \mathrm{~Gy}(A)$ or $4 \mathrm{~Gy}(B)$

recipients seeded with a "large" one $\left(35 \times 10^{6}\right)$ (Fig. 2), although the bone marrow cellularity and CFU content were approximately normal and were the same in both groups of mice (data not shown).

The content of PHSC in sublethally irradiated mice was estimated by competitive repopulation 19 weeks after 2 Gy 
irradiation in two experiments, and 10 or 19 weeks after $4 \mathrm{~Gy}$ irradiation in five experiments. The results obtained in a representative experiment are shown in Fig. 3. Immediately after irradiation with 2 Gy the number of CFUs was reduced ten times, and after $4 \mathrm{~Gy}, 100$ times as compared with normal bone marrow. Two months later, the CFU population was restored to a subnormal level in both groups of mice. The competitive repopulation of cells irradiated with the same doses but harvested from mice immediately after irradiation or 10-19 weeks later revealed equal content of PHSC. Thus, the cells responsible for the maintenance of long-term hematopoiesis in culture do not possess the capacity for regeneration after irradiation.

\section{Discussion}

This paper presents the first estimation of PHSC in murine bone marrow as measured by limiting dilution analysis of long-term cultures. The frequency of PHSC is approximately 10 per $10^{6}$ bone marrow cells. This number is in good agreement with data obtained in vivo by the limiting dilution method of reconstituted W-mutant mice [4-6]. The CFU population in bone marrow of studied genotypes reached 5000-8000 per femur. Taking the seeding efficiency factor as being $0.05-0.1$ [10], the CFU population would be 50000-150000 per femur. Therefore, each pluripotent HSC is capable of producing a clone which includes 500-1500 CFUs and $1-4 \times 10^{9}$ differentiating cells (it should be borne in mind that an 8-day spleen colony may consist of $4 \times 10^{6}$ cells). Such enormous hematopoietic clones can obviously easily support the continuous production of hematopoietic cells during the whole life span of a mouse by the sequential expansion of a relatively small number of PHSC formed during embryogenesis. The hematopoietic tissue of an adult mouse is presented by approximately $4 \times 10^{8}$ cells. If the replacement of all hematopoietic cells in the bone marrow occurs in only 4 days, one PHSC capable of producing a clone of $10^{9}$ cells would be enough for the maintenance of prolonged hematopoiesis for at least 10 days. Thus, only several hundred PHSC would be expended during the whole life span of a mouse. Therefore, although not yet conclusive, the results obtained support the hypothesis of hematopoiesis by clonal succession $[11,12]$.

The other important result obtained in this study suggests that PHSC are insensitive to cytostatics, in particular to phase-specific agents such as hydroxyurea which influence only cells synthesizing DNA. When the population of more mature precursors (CFUs) was nearly completely eliminated by cytostatics, the number of PHSC in bone marrow was unchanged. Therefore, PHSC apparently are in the $G_{0}$ phase of the cell cycle, and are members of a "hidden" reserve stem cell compartment. Their triggering into a state of proliferation could not be induced even by the strong hematopoietic stress. The data are in complete agreement with those obtained by competitive repopulation [3] and are not contradictory to the hypothesis that the population of "quiescent" primitive progenitors is formed during embryogenesis and is sequentially expended throughout postnatal development, producing one after another hematopoietic cell clones. If the latter were the case, then PHSC should not possess regeneration capacity. In the study performed, the increase of PHSC number until 19 weeks after 4 Gy irradiation was not really detected, although almost complete reconstitution of the CFU pool took place. The higher PHSC content in mice injected with a greater dose of bone marrow cells even several months after irradiation is also in accordance with this hypothesis because, if PHSC self-maintenance ability actually exists, the number of these cells would not depend on the injected cell dose.

On the whole, the data discussed above suggest that at present the hypothesis of hematopoiesis by clonal succes- 
sion seems to be the most simple and requires the minimum number of additional assumptions. For the reliable discrimination between this hypothesis and the idea of the existence of immortal HSC, new data are necessary. Retrovirus-mediated gene transfer may be a very suitable system for the exploration of this intriguing problem.

\section{References}

1. Chertkov JL (1986) Early hemopoietic and stromal precursor cells. Int Rev Cytol 102: $271-313$

2. Chertkov JL, Deryugina EI, Drize NJ, Udalov GA (1987) Individual clones of hemopoietic cells in murine long-term bone marrow culture. Leukemia 1:491496

3. Chertkov JL, Drize NJ, Gurevitch OA, Udalov GA (1986) Cells responsible for restoration of haemopoiesis in long-term murine bone marrow culture. Leuk Res 10:659-663

4. Boggs DR, Boggs SS, Saxe DF et al. (1982) Hematopoietic stem cells with high proliferative potential. Assay of the concentration in marrow by the frequency and duration of cure of $\mathrm{W} / \mathrm{W}^{\mathrm{v}}$ mice. J Clin Invest 70:242-253

5. Mintz B, Covarrabias L, Hawley RG (1987) Hematopoietic stem cells as po- tential vehicles for recombinant genes in prenatal mice. Haematologica 72 [Suppl]: 89-94

6. Nakano T, Naki N, Asai H, Kitamura $Y$ (1987) Long-term monoclonal reconstitution of erythropoiesis in genetically anemic W/Wv mice by injection of 5-fluorouracil-treated bone marrow cells of Pgk-1 1 Pgk- $1^{a}$ mice. Blood 70:1758-1763

7. Till JE, McCulloch EA (1961) A direct measurement of the radiation sensitivity of normal mouse bone marrow cells. Rad Res 14:213-222

8. Dexter TM, Allen TD, Lajtha LT (1977) Conditions controlling the proliferation of hemopoietic stem cells in vitro. J Cell Physiol 91:335-344

9. Chertkov JL, Drize NJ, Gurevitch OA, Udalov GA (1983) Hemopoietic stromal precursors in long-term culture of bone marrow. I. Precursor characteristics, kinetics in culture, and dependence on quality of donor hemopoietic cells in chimeras. Exp Hematol 11:231-242

10. Siminovitch L, McCulloch EA, Till JE (1963) The distribution of colony-forming cells among spleen colonies. J Cell Comp Physiol 63: 327-336

11. Kay HEM (1965) How many cell generations? Lancet II: 418-419

12. Micklem HS, Lennon JE, Ansell JD, Gray RA (1987) Numbers and dispersion of repopulating hematopoietic cell clones in radiation chimeras as function of injected cell dose. Exp Hematol 15: 251-257 